\title{
EFFECTS OF PROTECTIVE PANELS ON CHARRING OF TIMBER ELEMENTS IN TIMBER FRAME ASSEMBLIES
}

\author{
K. DE PROFT ${ }^{1}$, R. STEENSELS ${ }^{2} \&$ B. VAN DOREN ${ }^{2}$ \\ ${ }^{1}$ WOOD. BE - Belgian Institute for Wood Technology, Hof ter Vleestdreef, Brussels. \\ ${ }^{2}$ Hasselt University - Faculty of Engineering Technology, Martelarenlaan, Hasselt, Belgium.
}

\begin{abstract}
Panels protect timber elements in timber frame assemblies during fire. The influence of the panels can be incorporated into calculations according to EN 1995-1-2, Annex C [1]. The number of panels incorporated in this standard is limited. Moreover, the calculations performed according to this standard result in overestimation of the charred area. In this work, experimental analysis of the protective behaviour was performed. Small-scale fire tests were used to monitor the temperature inside the timber element and the timber frame assembly. The measured results are compared with calculations according to the standard.

Keywords: fire design, protective panels, timber frame construction.
\end{abstract}

\section{INTRODUCTION}

Eurocode 5 (EN 1995-1-2 [1]) provides rules for structural fire design of timber structures. More specific, annex $\mathrm{C}$ introduces calculation rules for timber frame assemblies whose cavities are completely filled with insulation.

An important issue in the behaviour of timber frame assemblies during fire is the protection of the timber by panels. EN 1995-1-2 incorporates a methodology to take the effect of protecting panels into account.

The methodology is based on two important parameters related to the specific panel. The first parameter is the time of start of charring, $t_{c h}$. The time of start of charring describes the time that the timber element, protected by the panel, starts to char. More precisely, the time of start of charring is defined when the temperature behind the panel reaches $300^{\circ} \mathrm{C}$. The second parameter is the time of failure of the protection, $t_{f}$.

For the moment, only a limited number of panels are referenced in EN 1995-1-2. In this paper, the charring of timber protected by different types of panels is studied experimentally. Small-scale fire tests are performed to study the behaviour of the panels and the behaviour of the protected timber element. A large number of thermocouples are positioned in the timber frame assembly and in the timber element in order to follow the temperatures at different locations at different times. All timber frame assemblies are filled with stone wool insulation.

\section{DESIGN MODEL IN EN 1995-1-2}

The cladding protecting the timber element is characterized by two parameters: the time of start of charring $t_{c h}$ and the time of failure of the protection $t_{f}$. The time of start of charring is the time that the timber element, protected by the panel, starts to char. More precisely, the time of start of charring is defined when the temperature behind the panel reaches $300^{\circ} \mathrm{C}$. The time of failure is reached when the panel fails or when the connection of the panel fails so that the panel falls down.

It is clear that the timber element is completely protected as long is the time of start of charring is not reached. When the time of start of charring is reached, the timber element starts to char. However, as long as the failure time of the panel is not reached, the timber 
element is still partly protected by the panel. The depth of charring $\mathrm{d}_{\text {char }}$ (see definition in Fig. 1) for this case $\left(t_{c h} \leq t \leq t_{f}\right)$ is given by:

$$
\mathrm{d}_{\text {char }}=k_{s} k_{2} \beta_{0}\left(t-t_{c h}\right)
$$

With $\mathrm{k}_{\mathrm{s}}$ the cross-section factor, $\mathrm{k}_{2}$ the insulation factor and $\beta_{0}$ the one-dimensional charring rate. The one-dimensional charring rate is $\beta_{0}=0.65 \mathrm{~mm} / \mathrm{min}$ for solid softwood with a minimal characteristic density of $290 \mathrm{~kg} / \mathrm{m}^{3}$.

When the time of failure of the panel is reached $\left(t>t_{f}\right)$, the charring depth $d_{\text {char }}$ can be found by:

$$
\mathrm{d}_{\text {char }}=\mathrm{k}_{\mathrm{s}} \mathrm{k}_{3} \beta_{0}\left(\mathrm{t}-\mathrm{t}_{\mathrm{f}}\right)+\mathrm{k}_{\mathrm{s}} \mathrm{k}_{2} \beta_{0}\left(\mathrm{t}_{\mathrm{f}}-\mathrm{t}_{\mathrm{ch}}\right)
$$

With $\mathrm{k}_{3}$ the post protection factor.

The cross-section factor $\mathrm{k}_{\mathrm{s}}$ takes the effect of the two-dimensional thermal heat transfer into account. The factor is given in EN 1995-1-2 for different widths of the timber element.

More conservative values for the cross-section factor are introduced in Ref. [2]. An experimental study showed that the stone wool insulation provides less protection of the wide sides of the timber elements. The following expression was proposed for the cross-section factor [2] for a timber element width $b$ between $38 \mathrm{~mm}$ and $90 \mathrm{~mm}$ :

$$
\mathrm{k}_{\mathrm{s}}=0.00023 \mathrm{~b}^{2}-0.045 \mathrm{~b}+3.19
$$

Table 1 summarizes values of the cross-section factor for different widths of the timber frame member.

The insulation factor $\mathrm{k}_{2}$ is given by:

$$
\mathrm{k}_{2}=1.05-0.0073 \mathrm{~h}_{\mathrm{p}}
$$

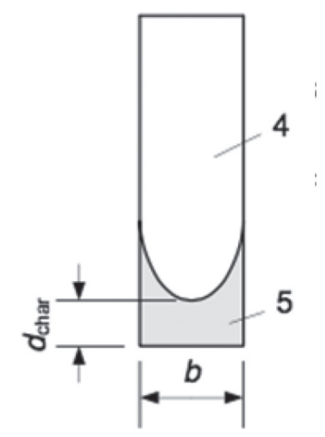

Figure 1: Definition of $\mathrm{d}_{\text {char }}$

Table 1: Cross-section factor for different widths of the timber frame member.

\begin{tabular}{lll}
\hline & $\mathbf{k}_{\mathbf{s}}$ & \\
\cline { 2 - 3 } $\mathbf{b}(\mathbf{m m})$ & $\mathbf{E N ~ 1 9 9 5 - 1 - 2}$ & Relation [2] \\
\hline 38 & 1.4 & 1.81 \\
45 & 1.3 & 1.63 \\
60 & 1.1 & 1.32 \\
\hline
\end{tabular}




$$
\mathrm{k}_{2}=0.86-0.0037 \mathrm{~h}_{\mathrm{p}}
$$

Where expression (4a) is for configurations without panel joints on the timber member and expression (4b) is for configurations with panel joints on the timber member.

The post-protection $\mathrm{k}_{3}$ is given by:

$$
\mathrm{k}_{3}=0.036 \mathrm{t}_{\mathrm{f}}+1
$$

For wood-based panels, the time of start of charring and the time of failure are equal and given by:

$$
t_{c h}=\mathrm{t}_{\mathrm{f}}=\frac{\mathrm{h}_{\mathrm{p}}}{\beta_{0}}-4
$$

For gypsum plasterboards of type A and type $\mathrm{H}$, the time of start of charring and the time of failure are equal and given by:

$$
t_{c h}=\mathrm{t}_{\mathrm{f}}=2,8 \mathrm{~h}_{\mathrm{p}}-14
$$

For gypsum plasterboards of type F, the charring time is given by expression (7). The time of failure is a parameter that should be declared by the manufacturer.

\section{EXPERIMENTAL STUDY}

\subsection{Test set-up}

Small-scale fire tests are performed on four different wall configurations. The tested configurations are given in Table 2. Within these configurations, the width of the timber element and the protective panels are altered. The test specimens are $1.2 \mathrm{~m} \times 1.2 \mathrm{~m}$. Two configurations have one intermediate stud with a width of $60 \mathrm{~mm}$. Two configurations have two intermediate studs with a width of $28 \mathrm{~mm}$. The height of all studs is $120 \mathrm{~mm}$. The cavity between the studs is filled with stone wool insulation with a density of $35 \mathrm{~kg} / \mathrm{m}^{3}$ or $45 \mathrm{~kg} / \mathrm{m}^{3}$. The following table shows an overview of the different configurations that were tested. The back side of all configurations was covered by a vapour open foil.

In all tests, the panels are oriented to the exposed side. The ISO-fire curve was used to simulate the fire.

Table 2: Overview of the tested configurations.

\begin{tabular}{lllll}
\hline Panel type & $\begin{array}{l}\text { Panel thick- } \\
\text { ness }(\mathbf{m m})\end{array}$ & $\begin{array}{l}\text { Stud } \\
\text { width } \\
\mathbf{( m m})\end{array}$ & $\begin{array}{l}\text { Density } \\
\text { insulation } \\
\left(\mathbf{k g} / \mathbf{m}^{3}\right)\end{array}$ \\
\hline 1 & $\begin{array}{l}\text { Gypsum plasterboard (type F) } \\
2\end{array}$ & 15 & 60 & 35 \\
3 & $\begin{array}{l}\text { Particleboard (type P5 - fire retardant) } \\
\text { Gypsum plasterboard (type H) + particle- }\end{array}$ & 22 & 28 & 45 \\
$\begin{array}{l}\text { board (type P5 - fire retardant) } \\
\text { Gypsum plasterboard (type A) + woodfibre } \\
\text { board + OSB (type 3) }\end{array}$ & $12.5+12$ & 28 & 45 \\
\hline
\end{tabular}




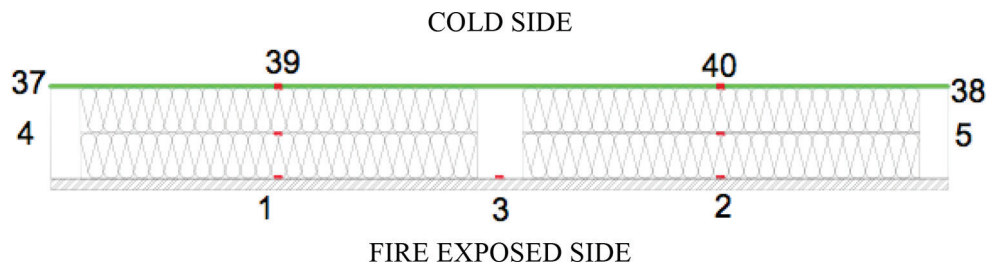

FIRE EXPOSED SIDE

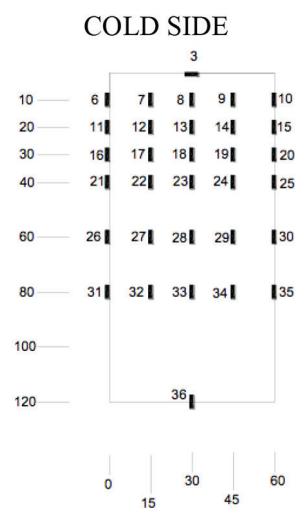

FIRE EXPOSED SIDE

Figure 2: Positioning of thermocouples for configuration 1: complete section of the wall (upper figure) and cross-section of the stud in the middle (all dimensions in $\mathrm{mm}$ ).

\section{COLD SIDE}

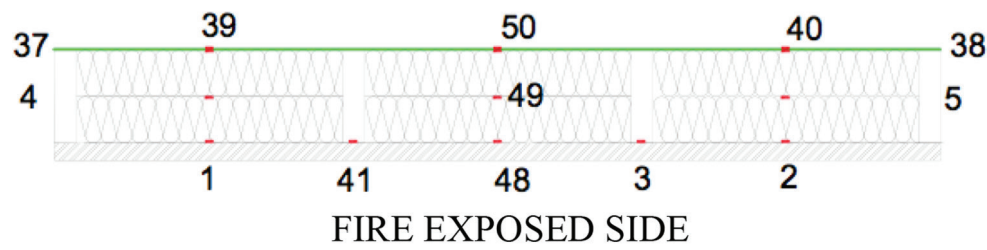

COLD SIDE
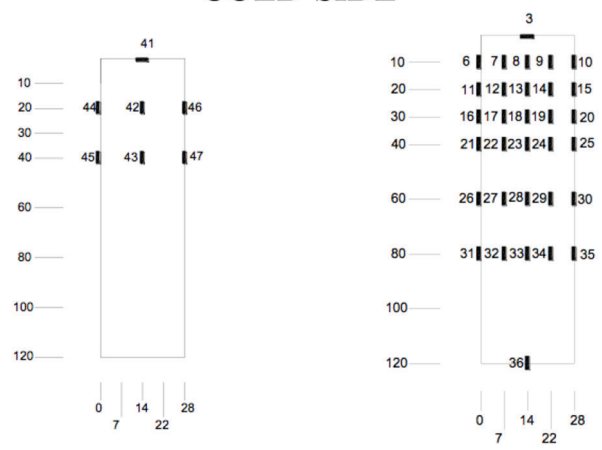

FIRE EXPOSED SIDE

Figure 3: Positioning of thermocouples for configuration 2: complete section of the wall (upper figure) and cross-section of the studs in the middle (all dimensions in $\mathrm{mm}$ ). 
COLD SIDE

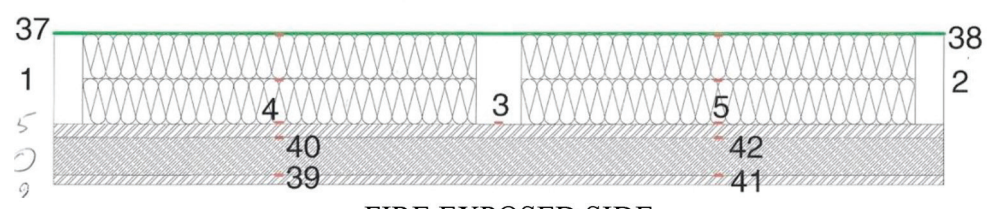

FIRE EXPOSED SIDE

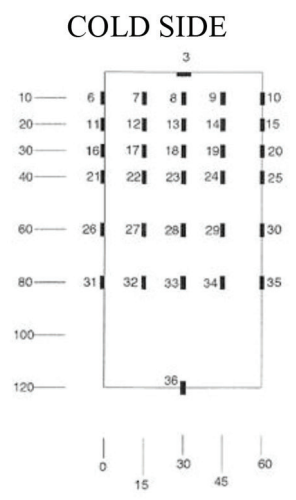

FIRE EXPOSED SIDE

Figure 4: Positioning of thermocouples for configuration 3: complete section of the wall (upper figure) and cross-section of the studs in the middle (all dimensions in $\mathrm{mm}$ ).
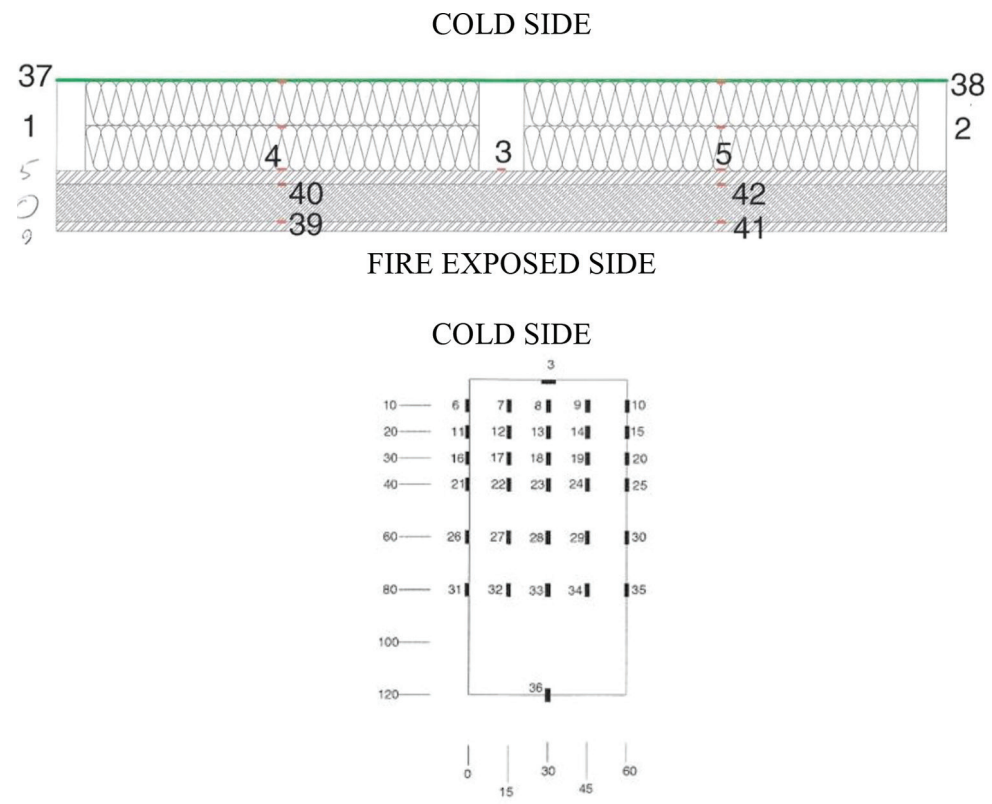

FIRE EXPOSED SIDE

Figure 5: Positioning of thermocouples for configuration 4: complete section of the wall (upper figure) and cross-section of the studs in the middle (all dimensions in $\mathrm{mm}$ ). 
In each configuration, a large number of thermocouples were used in order to measure the temperature evolution in function of the time. Figures 2 and 5 show the different locations of the thermocouples for the different configurations. The temperatures are measured each minute.

\subsection{Experimental results}

The average temperature behind the panel is calculated over all thermocouples that are positioned at the back side of the panel and shown in Figure 6. For clarity, also the ISO-fire curve is plotted in the figure.

The temperature behind the panel is the temperature between the system of panels and the stone wool insulation (for most configurations thermocouples 1, 2 and 3 are located behind the panel). The temperatures in Fig 6 are averaged on all thermocouples present at that location.

Clearly, the charring of the timber elements is postponed for all panels. The time of start of charring $\mathrm{t}_{\mathrm{ch}}$ can be derived from the measured temperatures. Table 3 summarizes for all configuration the time when the temperature behind the panel reaches $300^{\circ} \mathrm{C}$.

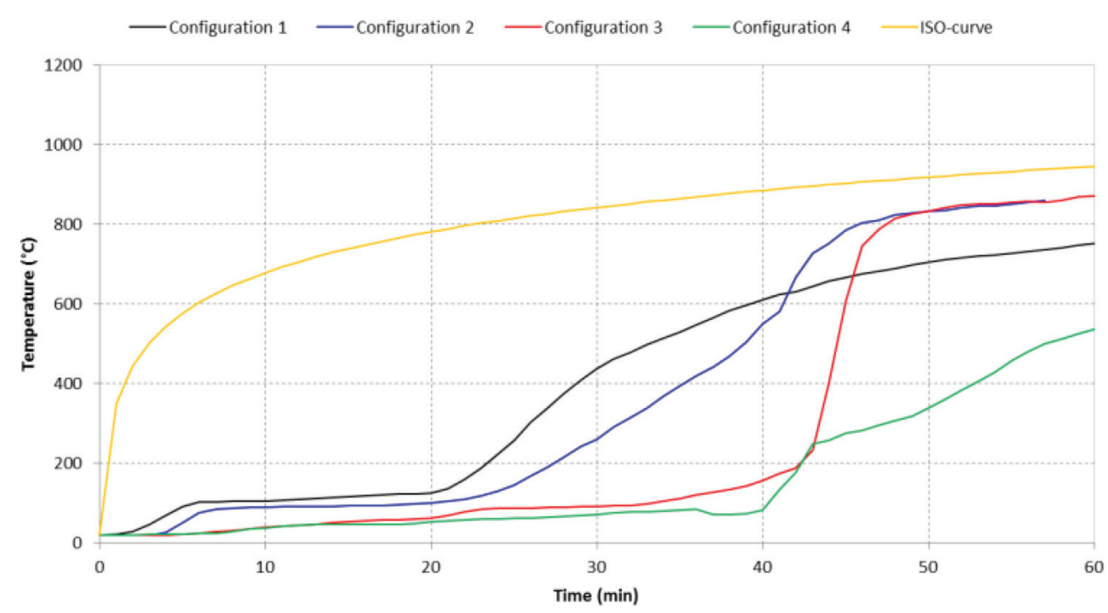

Figure 6: Average temperature behind the panel as a function of time.

Table 3: Overview of the tested configurations.

\begin{tabular}{lllll}
\hline & Configuration & $\begin{array}{l}\text { Panel thickness } \\
(\mathbf{m m})\end{array}$ & $\mathbf{t}_{\mathbf{c h}}(\mathbf{m i n})$ & $\mathbf{t}_{\mathbf{f}}(\mathbf{m i n})$ \\
\hline 1 & Gypsum plasterboard (type F) & 15 & 27.4 & 52 \\
2 & Particleboard (type P5 - fire retardant) & 22 & 34.5 & 51 \\
3 & $\begin{array}{l}\text { Gypsum plasterboard (type H) + particleboard } \\
\text { (type P5 - fire retardant) }\end{array}$ & $12.5+12$ & 43.4 & 58 \\
4 & $\begin{array}{l}\text { Gypsum plasterboard (type A) + woodfibre } \\
\text { board + OSB (type 3) }\end{array}$ & $12.5+50+18$ & 42.4 & 56 \\
\hline
\end{tabular}


The time of failure can also be derived from the measurements. However, this is more difficult. The time of failure can be defined in different ways. The time of failure can be determined as the time when the difference between the measure temperature behind the panel and the ISO-fire curve is less than 50K. Further, the time of failure is also reached when big parts of the panel fail. When examining the measured temperatures, failure cannot be determined.

Apart from the temperature behind the panel, the temperatures in the timber element are also measured. From the measurements, the evolution of the $300^{\circ} \mathrm{C}$ isotherm can be followed. Figure 7 shows the position of the $300^{\circ} \mathrm{C}$ isotherm at $60 \mathrm{~min}$ for configuration 1 . The temperatures for the remaining section are also shown.

Figure 8 shows the evolution of the charred area $\left(\mathrm{d}_{\text {char }}\right)$ in function of time for all configurations. Examining these figures, all curves can be divided into three parts. In the first part, no charring is present $\left(d_{\text {char }}=0\right)$. In the second part, the timber element starts charring. The rate of charring is nearly constant. In the third part, the charring continues but with an increase

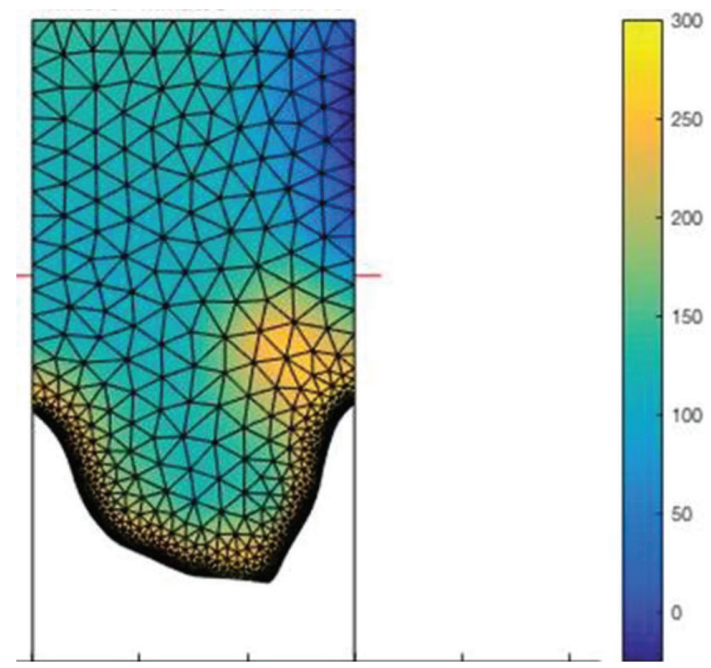

Figure 7: Temperature distribution in the timber element at 60 min for configuration 1.

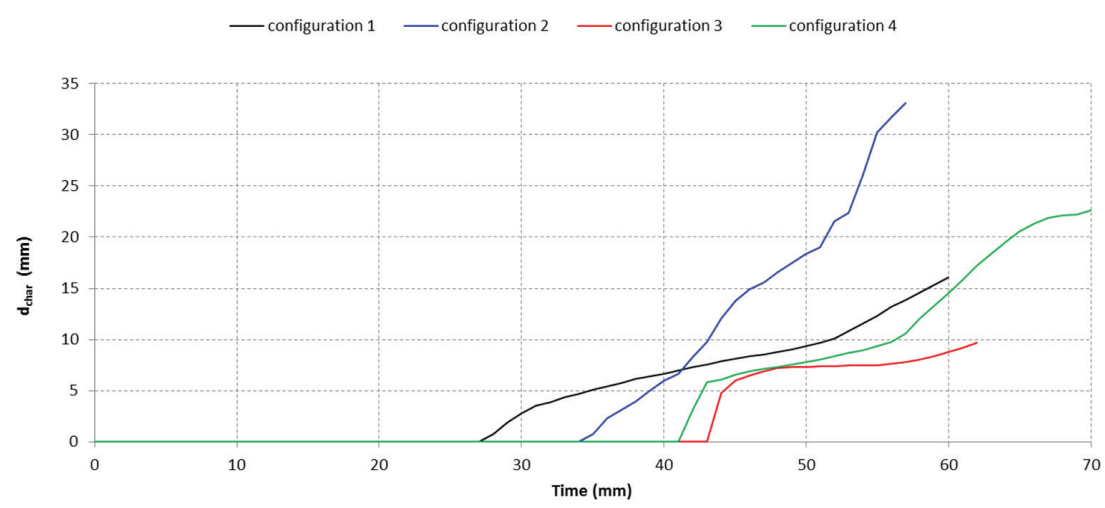

Figure 8: $\mathrm{d}_{\text {char }}$ as a function of time for the different configurations. 
charring rate. The second part can be related to the insulation factor $\mathrm{k}_{2}$. The timber is charring but still protected by the panel. The third phase is the post-protection phase, related to $\mathrm{k}_{3}$, where the panel has failed. Based on this reasoning, the time of failure can be defined as the time where the rate of charring changes. This definition is used to determine the time of failure in Table 3.

\section{COMPARISON BETWEEN EXPERIMENTAL AND COMPATIONAL RESULTS}

In this part, the experimental values are compared with computational results using EN 1995-1-2. Configurations 1, 2 and 4 are studied in detail. Some thermocouples in configuration 3 stopped working during the test so that no acceptable results can be shown.

Figure 9 shows the evolution of $\mathrm{d}_{\text {char }}$ in function of time for configuration 1 . The timber element starts charring at $\mathrm{t}=27.4 \mathrm{~min}$, which corresponds with the $\mathrm{t}_{\mathrm{ch}}=28$ min calculated with EN 1995-1-2. The measured charring rate is, however, lower than the rate predicted with EN 1995-1-2. The insulation factor $k_{2}$ is consequently overestimated. Once the panel failed,

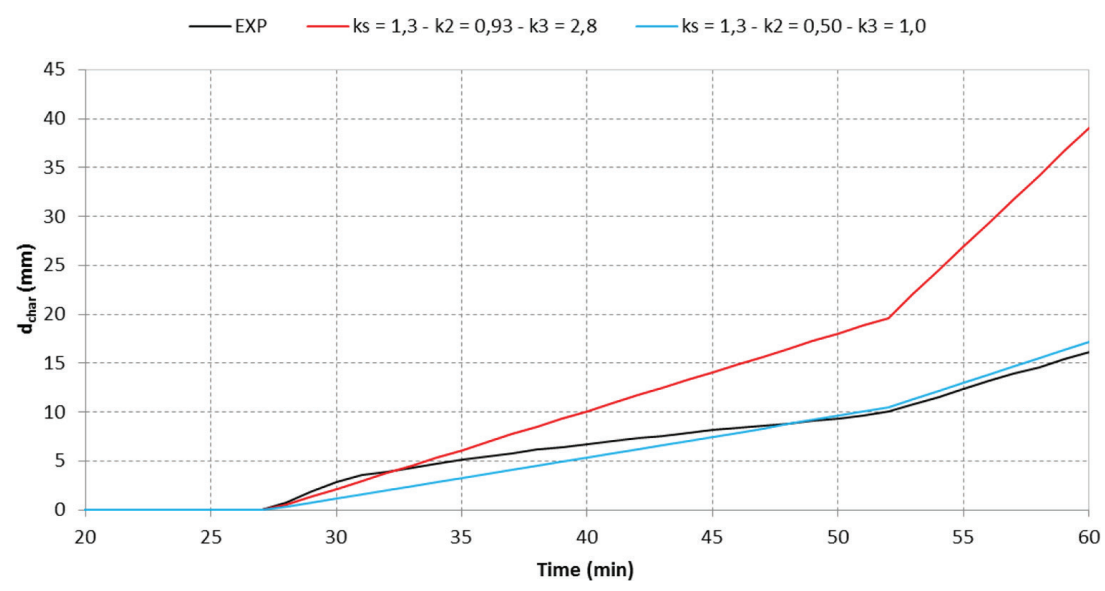

Figure 9: $d_{\text {char }}$ as a function of time for configuration 1.

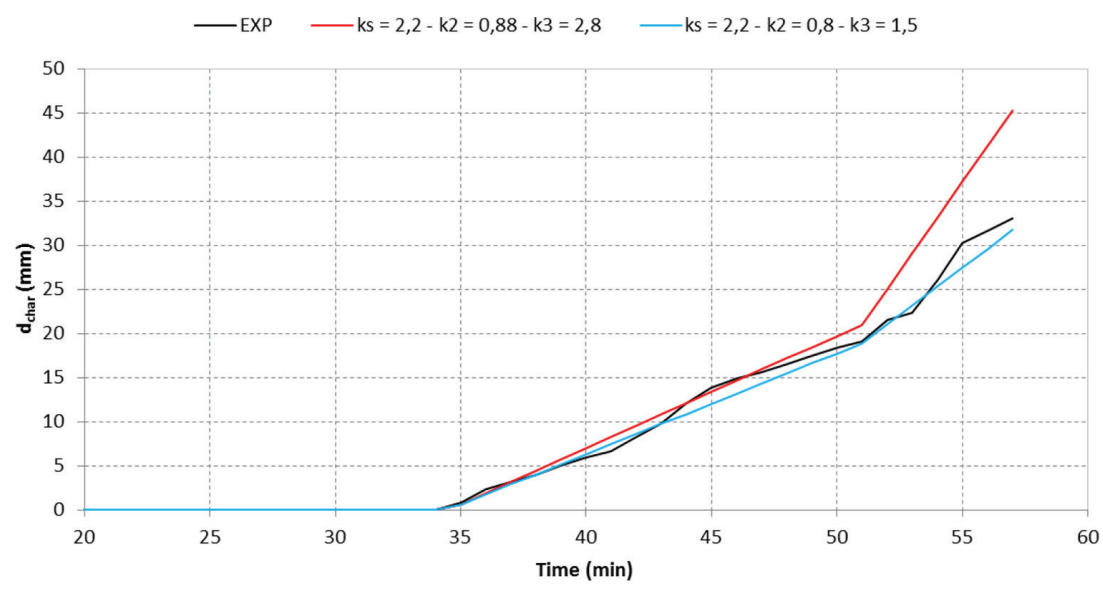

Figure 10: $d_{\text {char }}$ as a function of time for configuration 2 . 


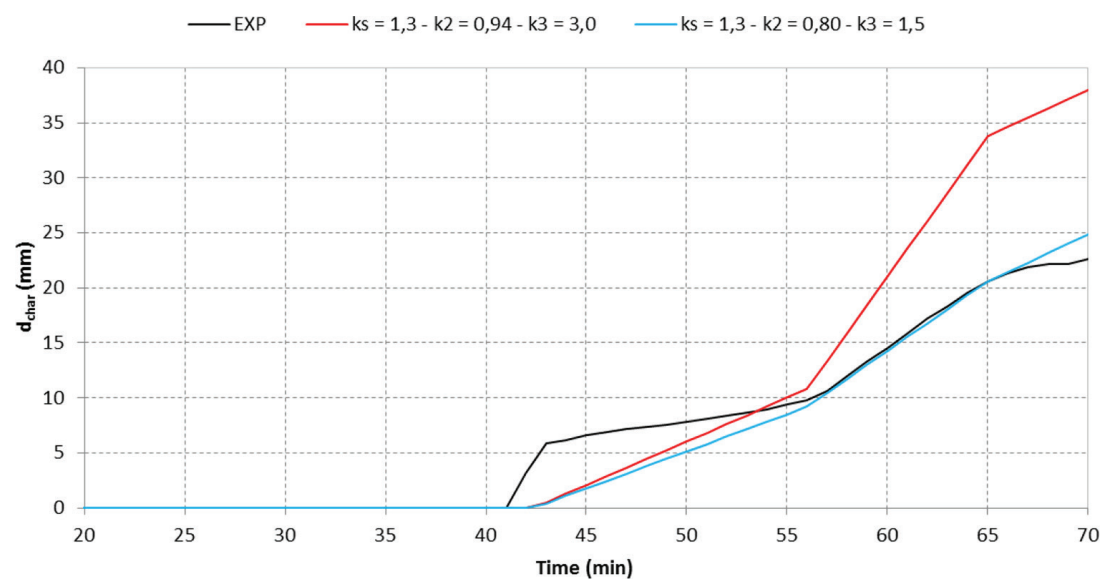

Figure 11: $d_{\text {char }}$ as a function of time for configuration 4.

$\mathrm{t}_{\mathrm{f}}=52 \mathrm{~min}$, the charring rate increases. The increase predicted by EN 1995-1-2 is again overestimated. Figure 9 also shows a curve with fitted $\mathrm{k}_{2}$ and $\mathrm{k}_{3}$ parameters.

Figure 10 shows $d_{\text {char }}$ as a function of time for configuration 2 . The timber element starts charring at $\mathrm{t}=34.5 \mathrm{~min}$. The time of charring calculated with $\mathrm{EN} \mathrm{1995-1-2} \mathrm{is}_{\mathrm{ch}}=24.3 \mathrm{~min}$, which is more conservative. An important parameter for the calculation of $t_{c h}$ is the characteristic panel density. The panel used in the test has a higher density explaining the big difference. EN 1995-1-2 assumes the time of failure equal to the time of start of charring. Clearly, this is not the case in het experiment. Consequently, the $d_{\text {char }}$ calculated with EN 1995-1-2 would result in an overestimation. Contrary to configuration 1, the insulation factor $\mathrm{k}_{2}$ gives a better estimation. The post-protection factor is again overestimated. Figure 10 also shows a curve with fitted $\mathrm{k}_{2}$ and $\mathrm{k}_{3}$ parameters.

Figure 11 shows the $d_{\text {char }}$ as a function of time for configuration 4. Due to the specific combination of panels, the time of start of charring cannot be predicted with EN 1995-1-2. Contrary to the previous configurations, a fourth phase can be identified in the figure. The timber starts charring at $t_{c h}=42.4 \mathrm{~min}$. The panels fail at $\mathrm{t}_{\mathrm{f}}=56 \mathrm{~min}$, where a sudden increase in charring rate is observed. The insulation factor $\mathrm{k}_{2}$ gives a good estimation for the charring rate between $t_{c h}$ and $t_{f}$. The post protection factor $k_{3}$ is again overestimated. After $65 \mathrm{~min}$, the charring rate decreases again. At that time, the char layer forms an insulation layer protected the timber element.

\section{CONCLUSIONS}

In this paper, the effect of protective panels on the charring of timber elements in timber frame assemblies was studied. Different wall configurations using different protective panels were tested in small-scale fire tests. During these tests, the temperature evolution was followed at different locations.

Thermocouples positioned behind the panels made it possible to determine the time of start of charring. Time of failure of the panel is more difficult to monitor based on these thermocouples.

Thermocouples positioned inside the timber element made it possible to follow the temperature inside the element and detect the $300^{\circ} \mathrm{C}$ isotherm in function of time. Timber is 
assumed to char at $300^{\circ} \mathrm{C}$. Based on the charring rate, the time of failure can be determined. EN 1995-1-2 assumes the time of start of charring and the time of failure equal for woodbased panels. Experiments show that there is a difference.

The measured charring rates are compared with the calculation model proposed in EN 1995-1-2. Two factors, the insulation factor $k_{2}$ and the post-protection factor $k_{3}$, are evaluated. In most cases, the insulation factor gives a good estimation of the charring rate between time of start of charring and time of failure. The post-protection factor resulted for all experiments in an overestimation. Furthermore, it was observed that the charring rate decreases again once a sufficient char layer was formed. More experiments will be done to examine the effect of the thickness of this char layer.

\section{ACKNOWLEDGEMENTS}

The authors would like to acknowledge NBN (www.NBN.be) and FOD economy for the financial support to this project.

\section{REFERENCES}

[1] EN 1995-1-2, Design of timber structures: part 1-2: General - structural fire design, 2009.

[2] Just, A., The effect of insulation on charring of timber frame members, SP Report 2010:30, Stockholm, 2010. 